\title{
Efficacy and safety of sodium valproate plus lamotrigine in children with refractory epilepsy
}

\author{
DONGLI ZHANG* ${ }^{*}$ LI QIU*, YUAN ZHANG, YAN SANG, NUO ZHENG and XIAOMING LIU \\ Department of Neurology, Xuzhou Children's Hospital, Xuzhou Medical University, Xuzhou, Jiangsu 221000, P.R. China
}

Received November 12, 2019; Accepted December 3, 2019

DOI: $10.3892 /$ etm.2020.8984

\begin{abstract}
Efficacy and safety of sodium valproate (SV) and lamotrigine (LTG) in treating refractory epilepsy (RE) in children and the predictive value of serum neuron-specific enolase (NSE) and central nervous system specific S100 $\beta$ protein $(\mathrm{S} 100 \beta)$ on efficacy assessment were explored. A total of 110 RE children admitted to Xuzhou Children's Hospital, Xuzhou Medical University were enrolled. Patients treated with SV alone served as the control group $(n=51)$, and those treated with SV plus LTG as the study group $(n=59)$. Serum NSE and S100 $\beta$ expression levels were measured by enzyme-linked immunosorbent assay (ELISA). The efficacy, seizure frequency, adverse reactions, concentration of serum brain derived neurotrophic factor (BDNF) and nerve growth factor (NGF), and expression of serum NSE and S100 $\beta$ were observed and compared. The total effective rate in the study group was significantly higher than that in the control group, and the seizure frequency and incidence of adverse reactions were significantly lower than that in the control group. The study group showed remarkably higher BDNF and NGF than the control group after treatment. The expression of serum NSE and $\mathrm{S} 100 \beta$ in effectively treated children were significantly lower than that in ineffectively treated children. The area under the curve (AUC) of serum NSE and S100 $\beta$ were 0.828 and 0.814 respectively. SV combined with LTG is better and safer than SV alone in the treatment of RE in children. Serum NSE and $S 100 \beta$ are of high value in predicting the efficacy.
\end{abstract}

\section{Introduction}

Epilepsy, a neurological disease with seizure susceptibility, has a negative impact on $0.6 \%$ of the population in

Correspondence to: Dr Xiaoming Liu, Department of Neurology, Xuzhou Children's Hospital, Xuzhou Medical University, 18 Sudi North Road, Quanshan, Xuzhou, Jiangsu 221000, P.R. China

E-mail:minglx@yeah.net

*Contributed equally

Key words: sodium valproate, lamotrigine, refractory epilepsy, NSE, S100 $\beta$ developed countries and $1.6 \%$ in developing countries $(1,2)$. Refractory epilepsy (RE) is a kind of drug-resistant epilepsy, which is defined as refractory because it has no successful therapeutic response to a variety of antiepileptic drugs (3). Ten to twenty percent (\%) of epileptic children progress to RE, and 470,000 children suffer from epilepsy, which means there are tens of thousands of RE children $(4,5)$. At present, antiepileptic drugs (AEDs) are the first-line therapy for RE, and the second-line is surgery, diet therapy, and vagus nerve stimulation (6). Although the treatment for RE has been continuously updated, the exploration of high-efficacy AED combinations is still ongoing (7). Our study explored the clinical efficacy and safety of AED regimens for RE children, which is of great value to improve their quality of life.

Sodium valproate (SV) is a first-line anti-epilepsy drug that can be applied to various seizure types in children, but it may also induce teratogenicity, neurocognitive impairment and other side effects (8). Studies have shown that SV plays a neuroprotective role by inhibiting endoplasmic reticulum stress and reducing neuronal apoptosis in epilepsy models induced by experiments (9). SV, an anticonvulsant through regulating neuronal pathways, has a close molecular structure with neurotransmitter $\gamma$-aminobutyric acid (GABA), resulting in GABA synergism, which inhibits the occurrence of epileptic onsets and epileptic states $(10,11)$. Lamotrigine (LTG) is a second-generation AED after SV, and also has the function of resisting depression and stabilizing mood $(12,13)$. It is applicable for children and adolescents with various seizure types and syndromes due to its good anticonvulsant, tolerance, broad spectrum activity, and safety (14). SV plus LTG, the most effective AED combination for RE, plays a synergistic role in pharmacodynamics and reduces the seizure frequency of children (15).

At present, there are few studies on the efficacy and safety of SV plus LTG in RE children. Therefore, we evaluated the clinical promotion value of these two AEDs by comparing the efficacy and clinical response.

\section{Patients and methods}

General data. A total of 110 RE children admitted to Xuzhou Children's Hospital, Xuzhou Medical University (Xuzhou, China) from February 2018 to March 2019 were enrolled. Patients treated with SV alone served as the control group, and those treated with SV plus LTG as the study group. There were 
35 males and 16 females in the control group, aged 3-11 years, with an average age of $6.12 \pm 1.05$ years, and 34 males and 25 females in the study group, aged 3-12 years, with an average age of $6.18 \pm 1.13$ years. The study was approved by the Ethics Committee of the Affiliated Xuzhou Children's Hospital of Xuzhou Medical University. The guardians were all informed and signed a fully informed consent form.

Inclusion and exclusion criteria. Inclusion criteria: conforming to the guidelines of RE developed by the International League Against Epilepsy (ILAE) (16); diagnosed by imaging examinations (17); receiving at least two AEDs in the past 6 months to one year; reaching maximum blood drug concentration, and the attacks reduced by at least half; aged 3-12 years. Exclusion criteria: complicated with malignant tumor or severe heart, lung, kidney and liver dysfunction; allergic to the drugs in this study; with incomplete clinicopathological data; pregnant women; not cooperating with this study.

Treatment methods. The patients in the control group were treated with SV alone (J65363, Jinsui Biotechnology Co., Ltd.). If $\mathrm{SV}$ was taken and the blood drug concentration range was $50-100 \mu \mathrm{g} / \mathrm{ml}$, other drugs were gradually discontinued. For patients who had not taken SV, the initial dose was $20 \mathrm{mg} / \mathrm{kg} / \mathrm{day}$, which was gradually increased until the blood drug concentration was in the range of $50-100 \mu \mathrm{g} / \mathrm{ml}$. The patients in the study group were treated with SV plus LTG (Jinsui Biotechnology Co., Ltd., J34775). If SV was taken and the blood drug concentration range was 50-100 $\mu \mathrm{g} / \mathrm{ml}$, LTG at $0.15 \mathrm{mg} / \mathrm{kg}$ was taken once a day, with a weekly increase of $0.20 \mathrm{mg} / \mathrm{kg} /$ day in the first month, $0.30 \mathrm{mg} / \mathrm{kg} /$ day in the second month and $0.50-1.00 \mathrm{mg} / \mathrm{kg} / \mathrm{day}$ in the third month. If the frequency of RE attacks and related symptoms were controlled or the total dose of LTG reached $10.00 \mathrm{mg} / \mathrm{kg} / \mathrm{day}$, LTG had to be stopped. If SV was not used before, the initial dose of SV was first taken, then LTG. The specific administration was as above.

Efficacy assessment. By comparing the average monthly seizure frequency after treatment with the first three months of treatment, the efficacy was quantified. Reduction of seizure frequency by $100 \%$, i.e., no seizures, was considered as control; Reduction of seizure frequency by $75-99 \%$ was considered as markedly effective; Reduction of seizure frequency by $50-74 \%$ was considered as considered effective; Reduction of seizure frequency by no more than $49 \%$ was considered as ineffective; Increase of seizure frequency by at least $25 \%$ was considered as deterioration. The total effective rate $=($ control + markedly effective+effective $) /$ total number of cases $\times 100 \%$.

Outcome measures. The seizure frequency in the two groups in the 3 months before treatment, and 3 and 6 months after treatment was observed and compared to assess the efficacy. The incidence of adverse reactions, serum brain derived neurotrophic factor (BDNF), nerve growth factor (NGF) concentration changes, and the expression of serum neuron-specific enolase (NSE) and central nervous system specific $S 100 \beta$ protein $(\mathrm{S} 100 \beta)$ in effectively and ineffectively treated children were compared.
Detection methods. Elbow venous blood $(5 \mathrm{ml})$ was drawn from the subjects before treatment from 8:00 to 9:00 a.m. 4 weeks after treatment, and placed in a vacuum tube without anticoagulant, then centrifuged at $1,500 \mathrm{x}$ g and $4^{\circ} \mathrm{C}$ for $10 \mathrm{~min}$. Sera were collected in an Eppendorf (EP) tube and stored at $-60^{\circ} \mathrm{C}$. After taken from the freezer, the sera were dissolved in a refrigerator at $4^{\circ} \mathrm{C}$, and then placed at room temperature for complete dissolution. The expression of BDNF, NGF, NSE, and S100 $\beta$ in serum was detected by enzyme-linked immunosorbent assay (ELISA) (18) in strict accordance with the instructions of the kits (Keshun Biotechnology Co., Ltd., KS017148, KS018187, KS015255, KS13441). Sample, standard and blank wells were set up. Test sample $(50 \mu \mathrm{l})$ and standard $(50 \mu \mathrm{l})$ were added to the sample well and standard well, respectively, no treatment for the blank well. The sample and standard wells were each added with $100 \mu \mathrm{l}$ of horseradish peroxidase labeled antibody, sealed and incubated at $37^{\circ} \mathrm{C}$ for $60 \mathrm{~min}$. The liquid was removed, the wells were dried and washed 5 times. Substrates A and B were fully mixed (1:1) and added to all wells (100 $\mu \mathrm{l}$ each well). Afterwards, the plate was sealed, incubation was carried out at $37^{\circ} \mathrm{C}$ for $15 \mathrm{~min}$, and $50 \mu \mathrm{l}$ of termination solution was added to each well. The optical density (OD) value at $450 \mathrm{~nm}$ of each well was read by a multifunctional ELISA analyzer (Shanghai Flash Spectrum Biotechnology Co., Ltd., SuPerMax 3000FL), and the concentrations of BDNF, NGF, NSE, and S100 $\beta$ were calculated.

Statistical analysis. This figures were visualized by GraphPad Prism 6 (GraphPad Software). Counting data were expressed by cases/percentage [n (\%)], and Chi-square $\left(\chi^{2}\right)$ test was used for comparison between groups. The measurement data were expressed by mean $\pm \mathrm{SD}$, and independent sample t-test was used for the comparison between the two groups. Receiver operating characteristic (ROC) curve was employed to assess the value of serum NSE and S100 $\beta$ in predicting the efficacy in patients. A value of $\mathrm{P}<0.05$ was considered to be statistically significant.

\section{Results}

Baseline data. There was no significant difference between the two groups in sex, average age, average course of disease, systolic blood pressure (SBP), diastolic blood pressure (DBP), seizure type, medication history, ADE combination, family history of RE, residence (P>0.05) (Table I).

Comparison of efficacy. Efficacy in the control group: the number of cases of control, markedly effective, effective, ineffective and deterioration were $15,10,6,14$ and 6, respectively, with a total effective rate of $60.78 \%$. Efficacy in the study group: the number of cases of control, markedly effective, effective, ineffective and deterioration were 23, 14, 11, 9 and 2, respectively, with a total effective rate of $81.35 \%$. The total effective rate in the study group was significantly higher than that in the control group $(\mathrm{P}<0.001)$ (Table II).

Comparison of seizure frequency. There was no significant difference in seizure frequency between the study group and the control group 3 months before treatment $(\mathrm{P}<0.05)$. At 
Table I. Comparison of baseline data $[\mathrm{n}(\%)$, mean \pm SD].

\begin{tabular}{|c|c|c|c|c|c|}
\hline Classification & $\mathrm{n}$ & Control group $(\mathrm{n}=51)$ & Study group $(\mathrm{n}=59)$ & $\chi^{2 / t}$ & P-value \\
\hline Sex & & & & 1.416 & 0.234 \\
\hline Male & 69 & $35(68.63)$ & $34(57.63)$ & & \\
\hline Female & 41 & $16(31.37)$ & $25(42.37)$ & & \\
\hline Average age (years) & 110 & $6.12 \pm 1.05$ & $6.18 \pm 1.13$ & 0.287 & 0.775 \\
\hline Average course of disease (years) & 110 & $3.01 \pm 0.45$ & $3.06 \pm 0.52$ & 0.535 & 0.594 \\
\hline $\mathrm{SBP}(\mathrm{mmHg})$ & 110 & $110.24 \pm 4.82$ & $109.56 \pm 5.06$ & 0.718 & 0.474 \\
\hline $\mathrm{DBP}(\mathrm{mmHg})$ & 110 & $75.02 \pm 4.45$ & $74.86 \pm 5.10$ & 0.174 & 0.862 \\
\hline Seizure type & & & & 0.124 & 0.989 \\
\hline Partial seizure & 66 & $31(60.78)$ & $35(59.32)$ & & \\
\hline Generalized seizure & 19 & $9(17.65)$ & $10(16.95)$ & & \\
\hline Secondarily generalized seizure & 13 & $6(11.76)$ & $7(11.86)$ & & \\
\hline Lennox Gastaut syndrome & 12 & $5(9.81)$ & $7(11.87)$ & & \\
\hline Medication history & & & & - & - \\
\hline Carbamazepine & 46 & $21(-)$ & $25(-)$ & & \\
\hline SV & 56 & $26(-)$ & $30(-)$ & & \\
\hline Topiramate & 30 & $17(-)$ & $13(-)$ & & \\
\hline Valnromide & 8 & $5(-)$ & $3(-)$ & & \\
\hline Phenytoin sodium & 6 & $3(-)$ & $3(-)$ & & \\
\hline Gabapentin & 6 & $2(-)$ & $4(-)$ & & \\
\hline AED combination & & & & 2.100 & 0.552 \\
\hline 2 & 67 & $30(58.82)$ & $37(62.71)$ & & \\
\hline 3 & 33 & $18(35.29)$ & $15(25.42)$ & & \\
\hline 4 & 6 & $2(3.92)$ & $4(6.78)$ & & \\
\hline 5 & 4 & $1 \quad(1.97)$ & $3(5.09)$ & & \\
\hline Family history of RE & & & & 0.283 & 0.595 \\
\hline No & 95 & $45(88.24)$ & $50(84.75)$ & & \\
\hline Yes & 15 & $6(11.76)$ & $9(15.25)$ & & \\
\hline Residence & & & & 0.294 & 0.588 \\
\hline Rural & 33 & $14(27.45)$ & $19(32.20)$ & & \\
\hline Urban & 77 & $37(72.55)$ & $40(67.80)$ & & \\
\hline
\end{tabular}

Table II. Comparison of efficacy [n (\%)].

\begin{tabular}{lccccccc}
\hline Group & $\mathrm{n}$ & Control & Markedly effective & Effective & Ineffective & Deterioration & Total effective rate \\
\hline Control group & 51 & $15(29.41)$ & $10(19.61)$ & $6(11.76)$ & $14(27.45)$ & $6(11.77)$ & 60.78 \\
Study group & 59 & $23(38.98)$ & $14(23.73)$ & $11(18.64)$ & $9(15.25)$ & $2(3.39)$ & 81.35 \\
$\chi^{2}$ value & - & - & - & - & - & - & 18.888 \\
P-value & - & - & - & - & - & - & $<0.001$ \\
\hline
\end{tabular}

3 and 6 months after treatment, the frequency in the study group was significantly lower than that in the control group $(\mathrm{P}<0.05)$ (Table III).

Incidence of adverse reactions. After treatment, RE children may present with loss of appetite, hyperactivity, hair loss, lower limb soreness, dizziness, rash and other adverse reactions, and loss of appetite, hyperactivity, lower limb soreness are the main ones. The incidence rate of adverse reactions in the study group was significantly lower than that in the control group (Table IV).

Comparison of neurotrophic indexes. Before treatment, the neurotrophic indexes BDNF and NGF were not significantly different between the two groups $(\mathrm{P}<0.05)$, which were significantly increased after treatment $(\mathrm{P}<0.001)$, and in the study group they were significantly higher than the control group $(\mathrm{P}<0.001)$ (Fig. 1). 
Table III. Comparison of seizure frequency (mean \pm SD).

\begin{tabular}{lcccc}
\hline Group & $\mathrm{n}$ & 3 months before treatment & 3 months after treatment & 6 months after treatment \\
\hline Control group & 51 & $15.43 \pm 2.29$ & $10.43 \pm 2.29$ & $6.97 \pm 1.15$ \\
Study group & 59 & $15.89 \pm 1.04$ & $7.89 \pm 1.04$ & $1.88 \pm 0.60$ \\
t value & - & 1.387 & 7.659 & 29.660 \\
P-value & - & 0.168 & $<0.001$ & $<0.001$ \\
\hline
\end{tabular}

Table IV. Adverse reactions [n (\%)].

\begin{tabular}{|c|c|c|c|c|}
\hline Classification & Control group $(n=51)$ & Study group $(n=59)$ & $\chi^{2}$ value & P-value \\
\hline Loss of appetite & $4 \quad(7.84)$ & $3(5.08)$ & 0.349 & 0.555 \\
\hline Hyperactivity & $4 \quad(7.84)$ & $2(3.39)$ & 1.052 & 0.305 \\
\hline Hair loss & $2(3.92)$ & 1 (1.69) & 0.511 & 0.475 \\
\hline Lower limb soreness & $3(5.88)$ & $2(3.39)$ & 0.531 & 0.392 \\
\hline Dizziness & $2(3.92)$ & 1 (1.69) & 0.511 & 0.475 \\
\hline Rash & $1 \quad(1.96)$ & $0 \quad(0.00)$ & 1.167 & 0.280 \\
\hline Total & $16(31.37)$ & $9(15.25)$ & 4.047 & 0.044 \\
\hline
\end{tabular}

Table V. Predictive value of serum NSE and S100 $\beta$ on efficacy assessment.

\begin{tabular}{lcccccc}
\hline Group & AUC & $95 \%$ CI & S.E & Cut-off & Sensitivity (\%) & Specificity (\%) \\
\hline NSE & 0.828 & $0.742-0.914$ & 0.044 & 26.05 & 79.75 & 77.42 \\
S100 3 & 0.814 & $0.731-0.896$ & 0.042 & 0.77 & 58.23 & 93.55 \\
\hline
\end{tabular}

NSE, neuron-specific enolase; S100 $\beta$, specific S100 $\beta$ protein.

Expression of serum NSE and S100 $\beta$. The treatment was effective in 79 children and ineffective in 31 children. The expression of serum NSE was $28.47 \pm 3.99$ and $21.03 \pm 3.18 \mu \mathrm{g} / 1$ in ineffectively treated and effectively treated children, respectively, while that of serum $S 100 \beta$ were $0.97 \pm 0.23$ and $0.65 \pm 0.26 \mu \mathrm{g} / 1$, respectively. Therefore, the expression of serum NSE and S100 $\beta$ in ineffectively treated children were significantly higher than that in effectively treated ones (Fig. 2).

Serum NSE and S100 $\beta$ in assessing the efficacy. ROC curve demonstrated that the AUC, cut-off, sensitivity, and specificity of serum NSE in assessing the efficacy were 0.828 (95\% CI, 0.742-0.914), 26.05, 79.75\%, and 77.42\%, respectively; while those of serum S100 $\beta$ were 0.814 (95\% CI, 0.731-0.896), $0.77,58.23$ and $93.55 \%$, respectively (Fig. 3 and Table V).

\section{Discussion}

$\mathrm{RE}$ is a chronic and debilitating disease of the nervous system with epileptic seizure caused by accidental discharge of cerebral neurons, which may lead to stigma in patients (19-21). Therefore, appropriate inhibition of neuronal excitability is the key in selection of AEDs in RE children (22). SV has been proved to alleviate neuronal apoptosis in a kainic acid model of epilepsy by enhancing phosphorylation of PKC-dependent GABA A R $\gamma 2$ Serine $327(23,24)$. LTG acts as glutamate antagonist to exert anticonvulsant and sedative functions through its pharmacological mechanism affecting sodium and calcium channels. It can also disturb the pathogenesis of hyperactivity via regulating excitatory neurotransmitters (25). In this study, hair loss, hyperactivity, and lower limb soreness were the main adverse reactions of patients. The seizure frequency in the study group was significantly lower than that in the control group, and the total effective rate and safety of treatment were significantly higher than those in the control group. Therefore, SV plus LTG has high efficacy and safety on RE children and has better inhibitory effect on the seizure frequency compared with SV alone.

We screened two neurotrophic indexes, BDNF and NGF, to compare the improvement of neurotrophic level of RE children treated with drugs that have inhibitory effects on neuronal excitability. BDNF mediates survival, growth, and regeneration of neurons and participates in the regulation of neural plasticity, playing an important role in the healthy brain development, and being of high diagnostic and prognostic value for brain injury $(26,27)$. Tan et al pointed out that BDNF protected neurons by inhibiting the secretion of excitatory amino acids, maintaining calcium homeostasis in neurons, as 

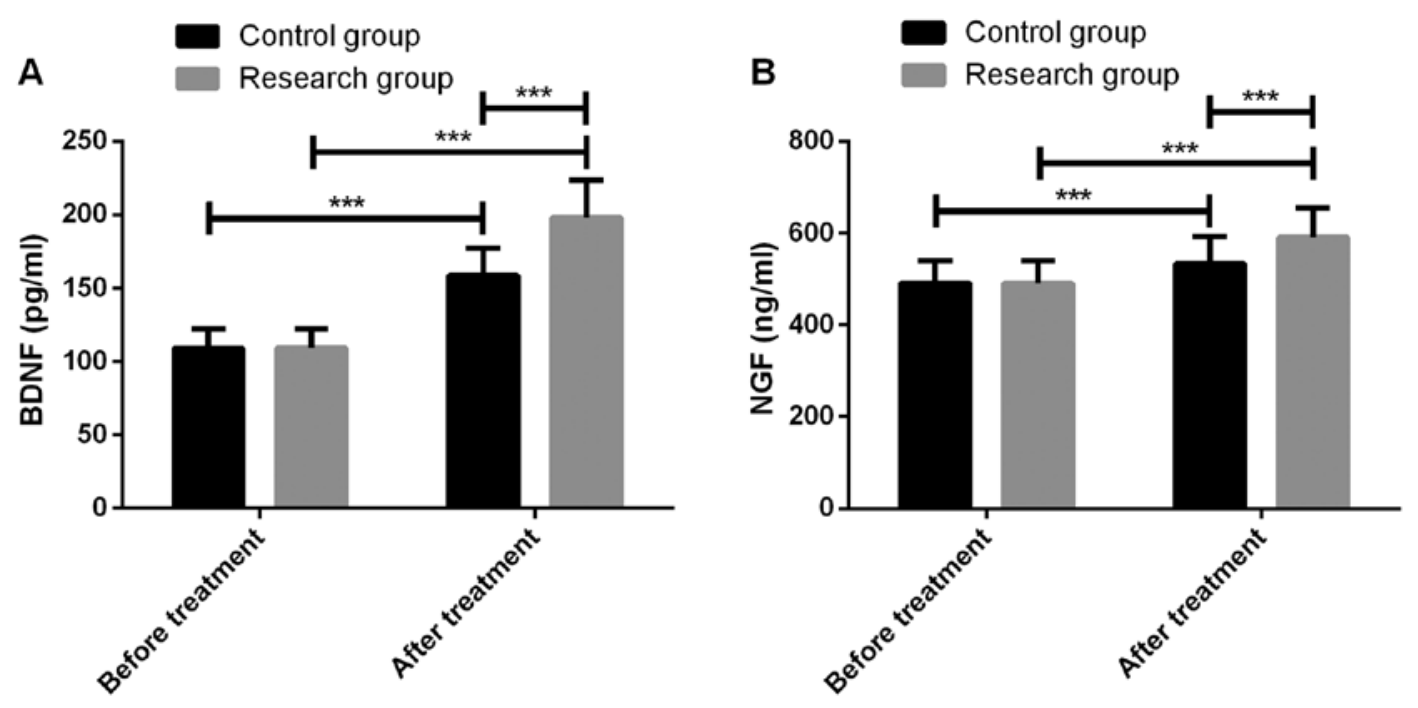

Figure 1. Comparison of neurotrophic indexes. (A) Comparison of BDNF before and after treatment. (B) Comparison of NGF before and after treatment. ${ }_{* * * *}^{*} \mathrm{P}<0.001$. BDNF, brain derived neurotrophic factor; NGF, nerve growth factor.
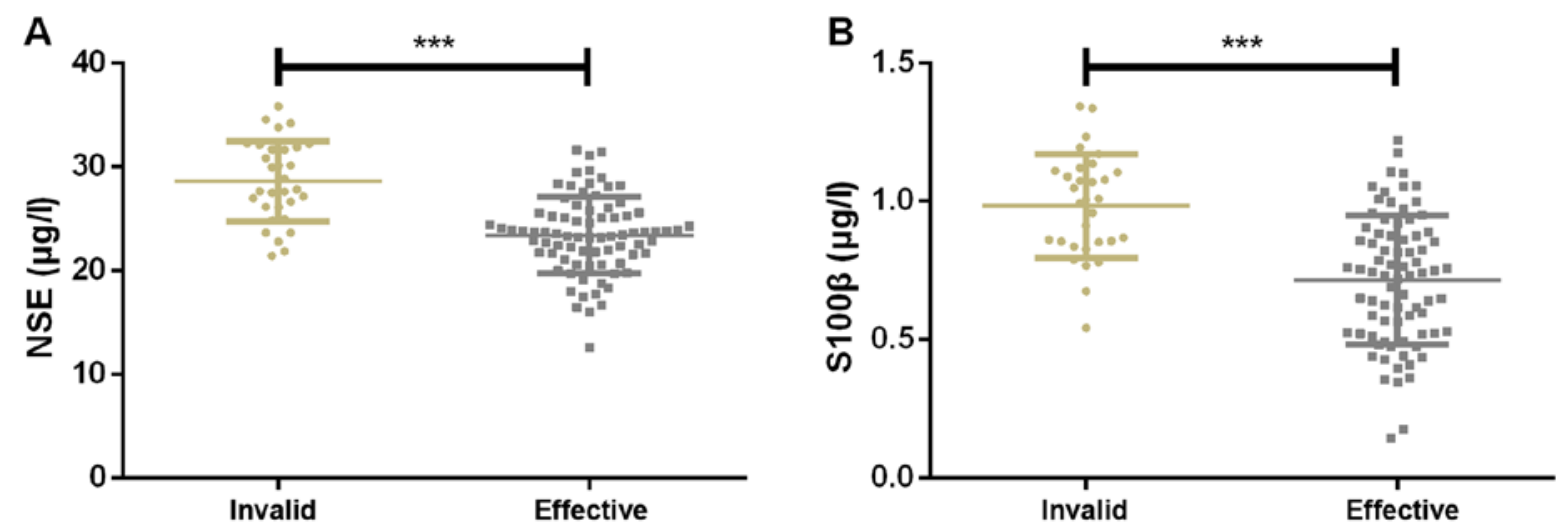

Figure 2. Expression of serum NSE and S100ß. (A) The expression of serum NSE in effectively treated children was significantly lower than that in ineffectively treated children. (B) The expression of serum $S 100 \beta$ in effectively treated children was significantly lower than that in ineffectively treated children. ${ }^{* * *} \mathrm{P}<0.001$. NSE, neuron-specific enolase. S100 $\beta$, specific S100 $\beta$ protein.
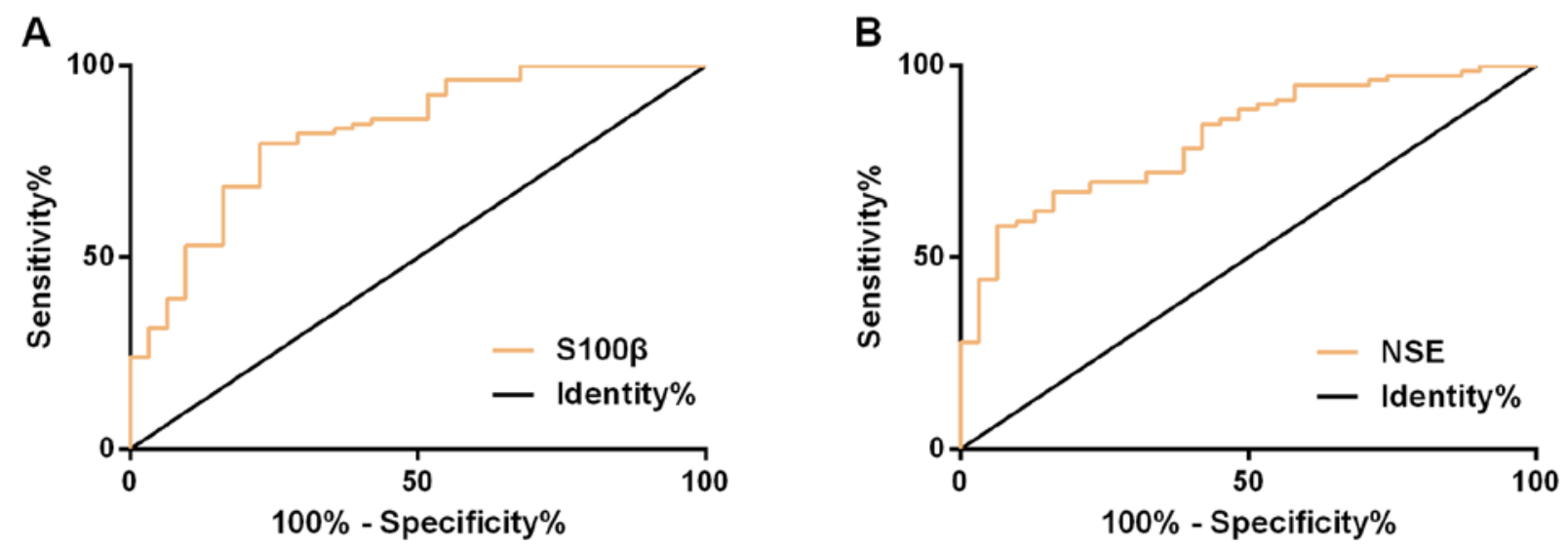

Figure 3. ROC curve of serum NSE and S100 $\beta$ in assessing efficacy. (A) ROC curve of serum NSE in assessing efficacy. (B) ROC curve of serum S100 $\beta$ in assessing efficacy. ROC, receiver operating characteristic; NSE, neuron-specific enolase. S100 $\beta$, specific S100 $\beta$ protein.

well as inhibiting the high expression of oxygen free radicals. Moreover, low BDNF level generally indicated the decline of cognitive function in epileptic patients (28). NGF, a typical representative of neurotrophic factors, is responsible for the growth, survival, and differentiation of mature neurons. In addition to being active in a wide array of non-nervous system 
cells, it is also synthesized by various cell types (29). NGF has a protective effect on basal forebrain cholinergic neurons and may reduce the susceptibility to generalized seizures $(30,31)$. BDNF and NGF were reported to be closely related to epilepsy and involved in the occurrence and progression of focal RE (32). Our findings showed that BDNF and NGF levels in the study group were more significantly increased, indicating that SV combined with LTG was more useful than SV alone in improving neurotrophic levels of RE children.

Finally, we assessed the predictive value of serum NSE and $\mathrm{S} 100 \beta$ on the efficacy in RE children. NSE and S100 $\beta$ are brain-derived proteins whose high expression is related to the increase of brain injury (33). Shaik et al found that serum NSE of patients with convulsion showed abnormally high expression, suggesting that it was a marker of epilepsy-related neuron injury (34). Another study demonstrated that serum S100 $\beta$ protein level of patients with focal epilepsy was significantly higher than that in healthy controls, which can be a biomarker for neuronal damage in patients with focal RE (35). In this study, the effectively treated children had a significantly lower expression of serum NSE and S100 $\beta$ than those with ineffective treatment, so serum NSE and $\mathrm{S} 100 \beta$ gradually recovered to normal levels in RE children after treatment. From the ROC curve, we obtained AUC of serum NSE and S100 $\beta$ and the efficacy was 0.828 and 0.814 , respectively, which showed that they had better predictive value in efficacy assessment for RE children.

This study confirmed that SV plus LTG has higher efficacy and fewer adverse reactions in the treatment of RE. However, statistics of various attack types and the efficacy of treatment in RE children need to be recorded to know which RE type of children treated by SV plus LTG achieves the highest curative effect.

In conclusion, SV combined with LTG is better and safer than SV alone in the treatment of RE in children, which is more worthy of clinical promotion. Serum NSE and S100 $\beta$ are of high value in predicting the efficacy.

\section{Acknowledgements}

Not applicable.

\section{Funding}

No funding was received.

\section{Availability of data and materials}

The datasets used and/or analyzed during the current study are available from the corresponding author on reasonable request.

\section{Authors' contributions}

DZ wrote the manuscript. DZ and LQ conceived and designed the study. YZ and YS were responsible for the collection and analysis of the experimental data. NZ and XL interpreted the data and drafted the manuscript. LQ and YS revised the manuscript critically for important intellectual content. All authors read and approved the final manuscript.

\section{Ethics approval and consent to participate}

The study was approved by the Ethics Committee of Xuzhou Children's Hospital, Xuzhou Medical University (Xuzhou, China). Patients who participated in this research, had complete clinical data. Signed informed consents were obtained from the parents or the guardians of the child patients.

\section{Patient consent for publication}

Not applicable.

\section{Competing interests}

The authors declare that they have no competing interests.

\section{References}

1. Armeno M, Verini A, Del Pino M, Araujo MB, Mestre G, Reyes G and Caraballo RH: A prospective study on changes in nutritional status and growth following two years of ketogenic diet (KD) therapy in children with refractory epilepsy. Nutrients 11: 1596, 2019.

2. McGovern RA, Banks GP and McKhann GM: Responsive stimulation in the management of medically refractory epilepsy. In: Epilepsy Surgery and Intrinsic Brain Tumor Surgery. Fountas K and Kapsalaki E (eds). Springer, Cham, pp205-211, 2019.

3. Sirven JI, Pedley TA and Wilterdink JL: Evaluation and management of drug-resistant epilepsy. UpToDate. https:// www.uptodate.com/contents/evaluation-and-management-of-drugresistant-epilepsy. Accessed August 13, 2018.

4. Mishra S: Refractory epilepsy in children: A short review. South Asian Res J Med Sci 1: 24-29, 2019.

5. Nigro SE: The efficacy of neurofeedback for pediatric epilepsy. Appl Psychophysiol Biofeedback 44: 285-290, 2019.

6. Moosa ANV: Antiepileptic drug treatment of epilepsy in children. Continuum (Minneap Minn) 25: 381-407, 2019.

7. Golyala A and Kwan P: Drug development for refractory epilepsy: The past 25 years and beyond. Seizure 44: 147-156, 2017.

8. Balagura G, Iapadre G, Verrotti A and Striano P: Moving beyond sodium valproate: Choosing the right anti-epileptic drug in children. Expert Opin Pharmacother 20: 1449-1456, 2019.

9. Fu J, Peng L, Wang W, He H, Zeng S, Chen TC and Chen Y: Sodium valproate reduces neuronal apoptosis in acute pentylenetetrazole-induced seizures via inhibiting ER stress. Neurochem Res 44: 2517-2526, 2019.

10. Brown C and Smith C: Sodium valproate. Pract Diabetes 35: 186-187, 2018.

11. Çavuș I, Romanyshyn JC, Kennard JT, Farooque P, Williamson A, Ȩid T, Spencer SS, Duckrow R, Dziura J and Spencer DD: Elevated basal glutamate and unchanged glutamine and GABA in refractory epilepsy: Microdialysis study of 79 patients at the yale epilepsy surgery program. Ann Neurol 80: 35-45, 2016.

12. Johannessen Landmark $C$ and Patsalos PN: Drug interactions involving the new second- and third-generation antiepileptic drugs. Expert Rev Neurother 10: 119-140, 2010.

13. Reimers A: Lamotrigine, bipolar disorder, and the pill-free week. Bipolar Disord 21: 372-373, 2019.

14. Yasam VR, Jakki SL, Senthil V, Eswaramoorthy M, Shanmuganathan S, Arjunan K and Nanjan MJ: A pharmacological overview of lamotrigine for the treatment of epilepsy. Expert Rev Clin Pharmacol 9: 1533-1546, 2016.

15. Poolos NP, Castagna CE, Williams S, Miller AB and Story TJ: Association between antiepileptic drug dose and long-term response in patients with refractory epilepsy. Epilepsy Behav 69: 59-68, 2017.

16. Lanteaume L, Guedj E, Bastien-Toniazzo M, Magalahaes A, Mundler O and Bartolomei F: Cognitive and metabolic correlates of emotional vulnerability in patients with temporal lobe epilepsy. J Neurol Neurosurg Psychiatry 83: 522-528, 2012.

17. Ollenberger GP, Byrne AJ, Berlangieri SU, Rowe CC, Pathmaraj K, Reutens DC, Berkovic SF, Scheffer IE and Scott AM: Assessment of the role of FDG PET in the diagnosis and management of children with refractory epilepsy. Eur J Nucl Med Mol Imaging 32: 1311-1316, 2005. 
18. Hornbeck PV: Enzyme-linked immunosorbent assays. Curr Protoc Immunol 110: 2.1.1-23, 2015.

19. Ramaratnam S, Panebianco $M$ and Marson AG: Lamotrigine add-on for drug-resistant partial epilepsy. Cochrane Database Syst Rev: CD001909, 2016.

20. Verrotti A, Iapadre G, Di Donato G, Di Francesco L, Zagaroli L, Matricardi S, Belcastro V and Iezzi ML: Pharmacokinetic considerations for anti-epileptic drugs in children. Expert Opin Drug Metab Toxicol 15: 199-211, 2019.

21. Pagura JR and Alessi R: Epilepsy and seizures. In: The Sports Medicine Physician. Piedade SR, Imhoff AB, Clatworthy M, Moises Cohen M and Espregueira-Mendes J (eds). Springer Cham, pp235-240, 2019.

22. Hernan AE and Holmes GL: Antiepileptic drug treatment strategies in neonatal epilepsy. Elsevier. Prog Brain Res 226: 179-193, 2016

23. Li Q, Li QQ, Jia JN, Cao S, Wang ZB, Wang X, Luo C, Zhou HH Liu ZQ and Mao XY: Sodium valproate ameliorates neuronal apoptosis in a kainic acid model of epilepsy via enhancing PKC-dependent GABAAR $\gamma 2$ Serine 327 phosphorylation. Neurochem Res 43: 2343-2352, 2018.

24. Rosenberg EC, Patra PH and Whalley BJ: Therapeutic effects of cannabinoids in animal models of seizures, epilepsy, epileptogenesis, and epilepsy-related neuroprotection. Epilepsy Behav 70B: 319-327, 2017.

25. Han SA, Yang EJ, Song MK and Kim SJ: Effects of lamotrigine on attention-deficit hyperactivity disorder in pediatric epilepsy patients. Korean J Pediatr 60: 189-195, 2017.

26. Korley FK, Diaz-Arrastia R, Wu AHB, Yue JK, Manley GT Sair HI, Van Eyk J, Everett AD, Okonkwo DO, Valadka AB, et al TRACK-TBI investigators: Circulating brain-derived neurotrophic factor has diagnostic and prognostic value in traumatic brain injury. J Neurotrauma 33: 215-225, 2016.

27. Bathina S and Das UN: Brain-derived neurotrophic factor and its clinical implications. Arch Med Sci 11: 1164-1178, 2015.
28. Tan XH, Song ZB, Wang H, Wang Q and He JL: Influence of adjuvant levetiracetam therapy on serum nerve cytokines and apoptosis molecules in patients with refractory partial epileptic seizure. Hainan Yixueyuan Xuebao 23: 145-149, 2017 (In Chinese).

29. Skaper SD: Nerve growth factor: A neuroimmune crosstalk mediator for all seasons. Immunology 151: 1-15, 2017.

30. Tuszynski MH, Yang JH, Barba D, U HS, Bakay RA, Pay MM, Masliah E, Conner JM, Kobalka P, Roy S, et al: Nerve growth factor gene therapy: Activation of neuronal responses in Alzheimer disease. JAMA Neurol 72: 1139-1147, 2015.

31. Silveira DC, Holmes GL, Schachter SC, Geula C and Schomer DL: Increased susceptibility to generalized seizures after immunolesions of the basal forebrain cholinergic neurons in rats. Brain Res 878: 223-227, 2000

32. Wang F, Lin Y, Kang D, Chen F, Lin K and Su X: Distribution and expression of brain-derived neurotrophic factor, nerve growth factor, and neurotrophic factor-3 in refractory epilepsy-associated focal cortical dysplasia. Clin Neuropathol 36: 233-239, 2017.

33. Alpdemir M, Özcan O, Alpdemir MF, Şeneş M, Azak A, Duranay $M$ and Yücel $M$ : Serum neuron specific enolase and S-100B levels in hemodialysis and peritoneal dialysis patients. Eur Arch Med Res 35: 83-87, 2019.

34. Shaik AJ, Reddy K, Mohammed N, Tandra SR, Rukmini Mridula Kandadai and Baba Kss S: Neuron specific enolase as a marker of seizure related neuronal injury. Neurochem Int 131: 104509, 2019.

35. Calik M, Abuhandan M, Kandemir H, Güzel B, Solmaz A, Celik H, Taskin A and Iscan A: Interictal serum S-100B protein levels in intractable epilepsy: A case-control study. Neurosci Lett 558: 58-61, 2014.

(i) (9) This work is licensed under a Creative Commons Attribution-NonCommercial-NoDerivatives 4.0 International (CC BY-NC-ND 4.0) License. 